\title{
Knowledge Attitude and Practice of General Physicians for Early Detection of Diabetic Nephropathy in Cotonou
}

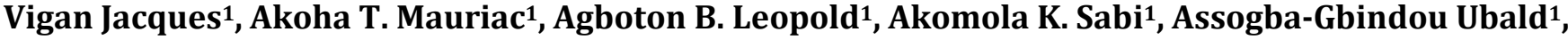 Attolou Vénérand', Djrolo François ${ }^{2}$}

${ }^{1}$ Nephrology Hemodialysis University Clinic of Hubert K. Maga Teaching Hospital (CNHU-HKM), Cotonou, Benin

${ }^{2}$ Endocrinology and Metabolism University Clinic of CNHU-HKM, Cotonou, Benin

Email: viques2@yahoo.fr

How to cite this paper: Jacques, V., Mauriac, A.T., Leopold, A.B., Sabi, A.K., Ubald, A.-G., Vénérand, A. and François, D. (2016) Knowledge Attitude and Practice of General Physicians for Early Detection of Diabetic Nephropathy in Cotonou. Open Journal of Nephrology, 6, 122-131. http://dx.doi.org/10.4236/ojneph.2016.64015

Received: September 18, 2016

Accepted: November 8, 2016

Published: November 11, 2016

Copyright (c) 2016 by authors and Scientific Research Publishing Inc. This work is licensed under the Creative Commons Attribution International License (CC BY 4.0).

http://creativecommons.org/licenses/by/4.0/

\section{Abstract}

Introduction: General physicians can play an important role in the early detection of diabetic nephropathy (DN). Purpose: To assess the levels of general physicians' knowledge, attitude and practice in terms of early detection of DN in Cotonou. Method: It was a cross-sectional, analytical and descriptive study which was conducted from 1st March 2015 to 30th September 2015. Every general physician working in a health structure in Cotonou who consented to participate in the study was included. We did not included medical specialists and general physicians working in nephrology department. Data were collected through a survey form designed with a score to assess the various items such as: knowledge, attitude and practice. The significance threshold is set to below 0.05 . Results: In total, 202 general physicians were included. The average age was $30.9 \pm 6.9$ years ranging from 24 to 68 years. A male predominance was observed with 2.2 sex ratio. The majority of respondent medical physicians had poor knowledge in $76.2 \%$ cases, bad attitudes $(61 \%)$ and bad practices $(64.9 \%)$ in terms of early detection of diabetic nephropathy. There was positive impact of continuing medical training focused on diabetic nephropathy on attitudes $(p=0.016)$ and practices $(\mathrm{p}=0.001)$ of these physicians. Conclusion: Diabetic nephropathy requires particular attention. General physicians' continuous training is a principal solution.

\section{Keywords}

Attitude, Benin, Knowledge, Early Detection, Practice, Diabetic Nephropathy

\section{Introduction}

Nowadays, the whole world is confronted with the development of non-communicable 
diseases such as: hypertension, diabetes mellitus, cancer and many other pathologies. The case of diabetes mellitus is quite worrying, especially in developing countries where the proper management of this disease is limited by the modest resources. In 2013, in sub-Saharan Africa, the total number of people with diabetes amounted to 19.8 million and this number will reach 41.5 million by 2035 , amounting to an increase of $109.6 \%$, according to 2013 estimates from the International Diabetes Federation [1].

Diabetes exposes patients to many complications including diabetic nephropathy (DN) which is one of the most dreaded types. It is a relatively common complication. In fact, diabetes is the cause of $54 \%$ of new cases of terminal chronic kidney disease requiring a kidney substitute in the United States of America [2].

Its severity is linked to its development towards terminal kidney disease which is likely to threaten the life of the patient in a short period of time if nothing is done, and exposes him to high risk of stroke.

In fact, nephro-protection measures help slowing kidney function deterioration and the risk of terminal chronic kidney failure, alongside human and economic consequences [3]. Early detection and proper management of diabetic nephropathy from the onset of its appearance improve its prognosis [4] [5] [6].

In Benin, diabetes prevalence which was $1.1 \%$ in 2001 soared to $2.6 \%$ in 2008 [7] [8]. The incidence of the microalbuminuria in type 2 diabetic patients is $47.03 \%$ according to a study conducted in Porto Novo and Cotonou [9]. The number of diabetologists is low and general physicians are key players in this early detection [10]. However, late recourse of diabetic nephropathy patients to nephrologists doubt on the knowledge, attitude and practice of these general physicians about diabetic nephropathy. This is the rationale behind this study.

\section{Objectives}

\subsection{General Objective}

Assess the level of knowledge, attitude and practice of general physicians for early detection of diabetic nephropathy in Cotonou.

\subsection{Specific Objectives}

- Assess the level of knowledge of general physicians in terms of early detection of diabetic nephropathy in Cotonou;

- Assess the level of attitude of general physicians in terms of early detection of diabetic nephropathy;

- Assess the level of practice of general physicians in terms of early detection of diabetic nephropathy.

\section{Framework and Method of Study}

This study was conducted in all public, private and denominational health centers.

It was a cross-sectional, descriptive and analytical study conducted from 1st March 2015 to 30th October 2015. All general physicians members of the College of Physi- 
cians, working in a health facility in Cotonou were included in the study, regardless of the entity type of the health facility: public, private for-profit or nonprofit. They all gave their informed consent to participate in the study. All medical specialists and general physicians working in a nephrology unit were not included.

The formula of Schwartz was used to determine the size of the sample:

$$
\mathrm{n}=\frac{\varepsilon^{2} \times p \times q}{i^{2}}
$$

$\mathrm{n}$ : indicate the size of the sample ;

$\varepsilon$. indicate the gap reduced to 1.96 threshold $\alpha=5 \%$;

$p$ : indicate general physicians rate having a bad knowledge of the screening of the DN in Sri Lanka which is $60.8 \%$ [11].

$$
q=1-p=0.392
$$

$i$ i: indicate the granted precision equal to $7 \%$

$$
\begin{gathered}
\mathrm{n}=\frac{1.96^{2} \times 0.608 \times 0.392}{0.07^{2}} \\
\mathrm{n}=186.85 .
\end{gathered}
$$

We adjusted to 202 the number of doctors to take into account not potential respondents estimated about $10 \%$ of the workforce.

The physicians were questioned on several items namely:

- Age, sex, marital status, medical training university, workplace, number of years experience, family history of diabetic nephropathy, participation in a continuing medical training, participation in a continuing medical training specifically on diabetic nephropathy;

- Knowledge: definition of diabetic nephropathy, risk factors, recommendations for detection, therapeutic means;

- Attitudes towards a new diabetic patient and an old diabetic patient monitored for long;

- Practice: systematic detection of diabetic nephropathy at first consultation, management of a diagnosed patient, monitoring methods, referral to the nephrologist.

An assessment score was purposely designed to assess all these items, and a practitioner was considered to have good knowledge, attitude or practice when the score is above $60 \%$.

We developed a grid containing several items. The form was submitted to a panel of experts including diabetologists, nephrologists, psychologists, bio-statistician for validation. A pre-test was conducted and the results were discussed. The survey form was used after complete validation by this panel. We conducted ourselves the filling out of datasheets to prevent potential biases. The questionnaire is made up of closed questions that are more appropriate for this type of survey. We use clinical cases to assess general physicians' attitudes and practices for the early detection of diabetic nephropathy.

First of all, we had to list all public, private and denominational health centers located in Cotonou. General practitioners' recruitment technique was exhaustive. Thus, 
all physicians available and meeting the inclusion criteria during the study period were identified. From the lists of physicians provided by the directors of various health centers, we scheduled an appointment with the physicians in view of administering our questionnaire.

Scores tallying was done manually. Data were entered using Epi Data 3.1 software. The statistical analysis was conducted using SPSS 16.0 software. With regard to the qualitative variables, we determined the different proportions. Their comparison was made using Chi 2 test. The significance threshold is 0.05 . The confidence interval is determined at $95 \%$.

During data collection, confidentiality was strictly respected. All information gathered within the framework of this study were processed in accordance with the Code of Ethics.

\section{Results}

We listed at the level of Cotonou health zones 202 respondent physicians in 48 health facilities.

\subsection{Characteristics of the Study Population}

The age of respondent general physicians ranged from 24 to 68 years with an average of $30.9 \pm 6.9$ years. Over half of the respondent physicians were aged from 25 to 35 years, amounting to $76.2 \%$. The majority of respondent practitioners were male $(68.8 \%)$ with a sex ratio of 2.2 and single (55.4\%).

Most of the respondent physicians generally attended continuing medical training (85.6\%), while very few of them attended at least a continuing medical training particularly on diabetic nephropathy (18.8\%) (Table 1$)$.

\subsection{General Physicians' Level of Knowledge in Terms of Early Detection of Diabetic Nephropathy}

The majority of respondent general physicians had low level of knowledge in terms of early screening of diabetic nephropathy (76.2\%).

Moreover, only $26.7 \%$ of physicians knew the marker of DN early detection which is microalbuminuria. Table 2 shows assessment criteria of general practitioners' level of knowledge.

\subsection{General Physicians' Attitude in Terms of Early Detection of Diabetic Nephropathy}

In our series, $38.6 \%$ of general physicians had good level of attitude in terms of early detection of diabetic nephropathy.

Among general physicians who participated in a continuing medical training in general, $43.4 \%$ had a good level of attitude. There was a statistically significant relation between the level of attitude and participation in continuing medical training ( $\mathrm{p}$ $=0.001)$. 
Table 1. Characteristics of the population.

\begin{tabular}{|c|c|c|}
\hline & Number $(\mathrm{N}=202)$ & Percentage (\%) \\
\hline \multicolumn{3}{|l|}{ Age (years) } \\
\hline$\leq 25$ & 18 & 8.9 \\
\hline$[25-35]$ & 154 & 76.2 \\
\hline$[35-45]$ & 18 & 8.9 \\
\hline$\geq 45$ & 12 & 6.0 \\
\hline \multicolumn{3}{|l|}{ Gender } \\
\hline Male & 139 & 68.8 \\
\hline Feminine & 63 & 31.2 \\
\hline \multicolumn{3}{|l|}{ Marital status } \\
\hline Single & 112 & 55.4 \\
\hline Live as a couple & 90 & 44.6 \\
\hline \multicolumn{3}{|c|}{ Participation in $\mathrm{CMT}^{*}$} \\
\hline Yes & 173 & 85.6 \\
\hline No & 29 & 14.4 \\
\hline \multicolumn{2}{|c|}{ Participation in $\mathrm{CMT}^{*}$ on $\mathrm{DN}^{* *}$} & $\mathbf{v}$ \\
\hline Yes & 38 & 18.8 \\
\hline No & 164 & 81.2 \\
\hline
\end{tabular}

${ }^{*}$ Continuing medical training, ${ }^{* *}$ Diabetic nephropathy.

Table 2. General physicians' knowledge in terms of early detection of diabetic nephropathy in Cotonou in 2015.

\begin{tabular}{ccc}
\hline & Number $(\mathbf{n}=\mathbf{2 0 2})$ & Percentage (\%) \\
\hline Level of Knowledge: & 154 & 76.2 \\
Good & 48 & 23.8 \\
Knowledge of: & 136 & \\
Definition & 77 & 67.3 \\
Risk Factors & 54 & 38.1 \\
Screening marker & 11 & 26.7 \\
Beginning of screening in type $1 \mathrm{D}^{*}$ & 141 & 5.4 \\
Beginning of screening in type 2 $\mathrm{D}^{*}$ & & 69.8 \\
\hline * & &
\end{tabular}

There is a statistically significant relation between good attitude and participation in continuous medical training on diabetic nephropathy $(\mathrm{p}=0.016)$.

The majority of general physicians with good level of knowledge had good level of 
attitude in terms of early screening of diabetic nephropathy (87.5\%). There is a statistically significant relation between the general physicians' level of knowledge and their level of attitude in terms of early detection of diabetic nephropathy $(\mathrm{p}<0.001)$.

\subsection{General Physicians' Practice in Terms of Early Detection of Diabetic Nephropathy}

Among respondent general physicians, almost 7 out of $10(64.9 \%)$ had a bad level of practice in terms of early detection of diabetic nephropathy.

Only $38.2 \%$ of respondent general physicians, who attended a continuing medical training in general had good level of practice in terms of early detection of diabetic nephropathy with a statistically significant relation between the participation in continuing medical training in general and the level of practice for early detection of diabetic nephropathy $(\mathrm{p}=0.021)$.

Over half of the respondent general physicians having followed a continuing medical training on diabetic nephropathy had a good level of practice in terms of early screening of diabetic nephropathy (57.9\%). There is a statistically significant relation between participation in the continuing medical training targeted on diabetic nephropathy and general physicians' good practice in terms of early detection of diabetic nephropathy ( $p$ $=0.001$ ).

Most of the respondent general physicians with good level of knowledge, had good level of practice in terms of early detection of diabetic nephropathy (66.7\%), and there is a statistically significant relationship between good knowledge and good practice in terms of early screening of diabetic nephropathy $(\mathrm{p}<0.001)$.

Among respondent general physicians with good level of attitude, $74.4 \%$ have good practice in terms of early screening of diabetic nephropathy. There is a statistically significant relation between good attitude and good practice in terms of early detection of diabetic nephropathy $(\mathrm{p}<0.001)$.

\section{Discussion}

We conducted a systematic recruitment of all physicians available during the period of study. The use of our own survey grid may be a limitation of this work.

But there is no known assessment grid of the level of knowledge, attitude and practice in terms of early detection of diabetic nephropathy. That is why we developed our own grid containing several items. The form was submitted to a panel of experts including diabetologists, nephrologists, psychologists, bio-statistician for validation. The use of clinical cases to assess general physicians' attitudes and practices on the screening of diabetic nephropathy strengthened the validity of answers provided.

\subsection{General Physicians' Level of Knowledge}

Most of the general physicians (76.2\%) had bad knowledge in terms of the detection of diabetic nephropathy. Moreover, very few physicians knew the importance of microalbuminuria in the early detection of diabetic nephropathy (26.2\%). 
This result is lower than that of KATULANDA who recorded a prevalence of $39.2 \%$ among general physicians who really know the importance of microalbuminuria in the detection of diabetic nephropathy in a study on knowledge and practices in terms of diabetes mellitus in Sri Lanka [11].

WONG recorded in 1999 in the USA a higher prevalence of $37 \%$ of general physicians who know the importance of microalbuminuria in the early diagnosis of diabetic nephropathy [12].

Another study conducted in Pas-de-Calais in France in 2006 by BATHAEI revealed a prevalence of $40.2 \%$ among general physicians who knew microalbuminuria as a marker of early detection of diabetic nephropathy [13].

Another study by KHANDEKAR in Oman on knowledge in terms of prevention of diabetic retinopathy showed the same trend with $33.3 \%$ of general physicians with acceptable knowledge [14].

These results may be explained by several factors in our environment:

- Inadequate training on diabetes mellitus,

- The scarcity of continuing medical training on diabetic nephropathy,

- The lack of specialists in the field of diabetology and nephrology,

- They could be used as training facilitators,

- The absence of algorithm on early detection of diabetic nephropathy.

\subsection{Level of Attitude}

Over six out of ten general physicians (61.4\%) had a bad level in terms of attitude of early detection of diabetic nephropathy. These results can be explained by the level of knowledge of these general physicians.

In Barbados, ADAMS in a study conducted on knowledge attitude and practice as well as obstacles identified by hypertensive patients and diabetic patients organized in focus group helped to reveal an inadequate attitude of healthcare personnel vis-à-vis patients [15].

Over half (55.3\%) of respondent general physicians who attended a continuing medical training on diabetic nephropathy had good attitudes for early detection of diabetic nephropathy with a significant relation $(\mathrm{p}=0.016)$. Continuing medical trainings targeted on diabetic nephropathy therefore impacted positively general physicians' attitude in terms of early detection of diabetic nephropathy.

Most general physicians who have good knowledge have good attitude in terms of early screening of diabetic nephropathy (87.5\%). Therefore the level of attitude improves with the level of knowledge. This statistically significant relation $(\mathrm{p}<0.001)$ is the evidence that attitudes largely depend on the level of knowledge.

\subsection{Level of Practice}

In our study, most general physicians had bad practices in terms of early screening of diabetic nephropathy with $64.9 \%$ prevalence. This could primarily be explained by the lack of continuing training on diabetic nephropathy during their medical practice. 
In a study conducted by general physicians in Israel on the management of diabetic patients with chronic kidney disease, EILAT observed that these physicians had a better ability to search parameters such as blood pressure and lipid profile instead of parameters related to kidney impairment which are proteinuria, haematuria, referral to the nephrologist [16].

In Indiana State in the USA, a study conducted by Kraft on general physicians, family doctors and internists found that only $17 \%$ and $12 \%$ requested microalbuminuria test from respectively their diabetic patients of type 1 and type 2 [17]. There was lack of microalbuminuria test request according to the recommendations. This study revealed that $60 \%$ of medical physicians resorted to test strips for the assessment of the albumin urinary excretion [17].

Most general physicians who attended a continuing medical training on diabetic nephropathy had good practice in terms of early screening of diabetic nephropathy (57.9\%) with a statistically significant relation $(\mathrm{p}=0.01)$.

KRAFT found in Indiana in the USA a significant relation between practices in terms of diabetic nephropathy and participation in continuing medical training modules ( $\mathrm{p}=$ 0.01 for type 1 diabetes and $\mathrm{p}<0.001$ for type 2 diabetes) [17].

The majority of general physicians who had good knowledge had good practice in terms of early detection of diabetic nephropathy with a statistically significant relation between the level of knowledge and the level of practice $(\mathrm{p}<0.001)$. The level of practice is thus improved with the level of knowledge.

SHERA showed that there was no significant difference between the knowledge of family doctors in Pakistan and their practices in terms of diabetes mellitus [18].

Almost 7 out of 10 practitioners (74.4\%) who have good attitude had good practice in terms of early detection of diabetic nephropathy $(\mathrm{p}<0.001)$. Good attitudes involve good practices.

\section{Conclusion}

The majority of respondent general physicians in Cotonou had low level of knowledge (76.2\%), attitude (61.4\%) and practice (64.9\%) in terms of early detection of diabetic nephropathy. Participation in continuing medical training targeted on diabetic nephropathy impacted positively on general physicians' attitudes and practices in terms of

early detection of the disease. It is therefore necessary to boost the continuing training system in view of improving the early detection of this disease.

\section{Conflict of Interest Declaration}

The authors declare not to have any conflict of interest in connection with this article.

\section{References}

[1] Noubiap, J.J.N., Naidoo, J. and Kengne, A.P. (2015) Diabetic Nephropathy in Africa: A Systematic Review. World Journal of Diabetes, 5, 759-773.

http://dx.doi.org/10.4239/wjd.v6.i5.759 
[2] Ritz, E. (2011) Limitations and Future Treatment Options in Type 2 Diabetes with Renal Impairment. Diabetes Care, 34, 330-334. http://dx.doi.org/10.2337/dc11-s242

[3] Abdesselem, H., Chaari, C., Fennira, E., Htira, Y., Sallem, O.K., Berriche, O., et al. (2014) L'évolution à long terme de l'albuminurie sous IEC dans une population de diabétiques tunisiens. Annales d Endocrinologie, 75, 389. http://dx.doi.org/10.1016/j.ando.2014.07.400

[4] United Kingdom Prospective Diabetes Study (UKPDS) Group (1998) Intensive BloodGlucose Control with Sulphonylureas or Insulin Compared with Conventional Treatment and Risk of Complications in Patients with Type 2 Diabetes (UKPDS 33). The Lancet, 352, 837-853. http://dx.doi.org/10.1016/S0140-6736(98)07019-6

[5] Diabetes Control and Complication Trial (DCCT) Group (1993) The Effect of Intensive Treatment of Diabetes on the Development and Progression of Long-Term Complications in Insulin-Dependent Diabetes Mellitus. The New England Journal of Medicine, 329, 977 986. http://dx.doi.org/10.1056/NEJM199309303291401

[6] Hwadmin (1998) Tight Blood Pressure Control and Risk of Macrovascular and Microvascular Complications in Type 2 Diabetes: UKPDS 38. BMJ, 317, 703-713.

http://dx.doi.org/10.1136/bmj.317.7160.703

[7] Djrolo, F., Amoussou Guenou, D.K., Zannou, D.M., Houinato, D., Ahouandogbo, F. and Houngbé, F. (2003) Prévalence du diabète au Bénin. Louvain médical, 122, S256-S260.

[8] Houinato, D., Segnon-Agueh, J., Djrolo, F. and Djigbennoudé, O. (2008) Rapport final de l'enquête STEPS au Bénin. Cotonou (Bénin): Ministère de la santé, Direction nationale de la protection sanitaire (DNPS), Programme national de lutte contre les maladies non transmissibles (PNLMNT). 69 p.

[9] Agboton, B.L., Wanvoegbe, A., Vigan, J., Hazoume, R., Agbodande, A., Mousse, L., AmoussouGuenou, D. and Djrolo, F. (2015) Microalbuminurie chez les patients diabétiques de type 2 au sud du Bénin: Aspects cliniques et paracliniques. Néphrologie et thérapeutique, 11, 360361. http://dx.doi.org/10.1016/j.nephro.2015.07.305

[10] Bouenizabila, E., Loumingou, R., Motoula, M., Andzouana, N. and Monabeka, H.-G. (2015) La néphropathie diabétique au CHU de Brazzaville, Congo : Aspects épidémiologiques, cliniques, et facteurs de risque. Médecine Mal Métaboliques, 9, 220-226. http://dx.doi.org/10.1016/S1957-2557(15)30048-1

[11] Katulanda, P., Constantine, G.R., Weerakkody, M., Perera, Y.S., Jayawardena, M.G., Wijegoonawardena, P., et al. (2011) Can We Bridge the Gap? Knowledge and Practices Related to Diabetes Mellitus among General Practitioners in a Developing Country: A Cross Sectional Study. Asia Pacific Family Medicine, 10, 10-15. http://dx.doi.org/10.1186/1447-056X-10-15

[12] Wong, T., Foote, E.F., Lefavour, G.S., Cody, R.P., Brown, C.J. and Sherman, R.A. (1999) Physician Knowledge and Practice Patterns Relating to Diabetic Nephropathy. Journal of the American Pharmacists Association, 39, 785-790.

[13] Bathaei, S., Vitry, J., Noel, C., Vambergue, A., Lemaire, C. and Romon, M. (2012) P44 Évaluation des connaissances des médecins généralistes (MG) sur la microalbuminurie (MA). Diabetes \& Metabolism, 38, A42. http://dx.doi.org/10.1016/S1262-3636(12)71146-1

[14] Khandekar, R., Deshmukh, R., Vora, U. and Al Harby, S. (2011) Knowledge of Primary Prevention of Diabetic Retinopathy among General Ophthalmologists, Mid Level Eye Care Personnel and General Physicians in Oman. Middle East African Journal of Ophthalmology, 18, 204-208. http://dx.doi.org/10.4103/0974-9233.84045

[15] Adams, O.P. and Carter, A.O. (2011) Knowledge, Attitudes, Practices, and Barriers Reported by Patients Receiving Diabetes and Hypertension Primary Health Care in Barbados: 
A Focus Group Study. BMC Family Practice, 12, 135.

http://dx.doi.org/10.1186/1471-2296-12-135

[16] Eilat-Tsanani, S., Reitman, A., Dayan, M., Mualem, Y. and Shostak, A. (2014) Management of Kidney Disease in Patients with Diabetes in the Primary Care Setting. Primary Care Diabetes, 8, 159-163. http://dx.doi.org/10.1016/j.pcd.2013.11.004

[17] Kraft, S.K., Lazaridis, E.N., Qiu, C., Clark, C.M. and Marrero, D.G. (1999) Screening and Treatment of Diabetic Nephropathy by Primary Care Physicians. Journal of General Internal Medicine, 14, 88-97. http://dx.doi.org/10.1046/j.1525-1497.1999.00292.x

[18] Shera, A.S., Jawad, F. and Basit, A. (2002) Diabetes Related Knowledge, Attitude and Practices of Family Physicians in Pakistan. Journal of Pakistan Medical Association, 52, 465470 .

Submit or recommend next manuscript to SCIRP and we will provide best service for you:

Accepting pre-submission inquiries through Email, Facebook, LinkedIn, Twitter, etc. A wide selection of journals (inclusive of 9 subjects, more than 200 journals)

Providing 24-hour high-quality service

User-friendly online submission system

Fair and swift peer-review system

Efficient typesetting and proofreading procedure

Display of the result of downloads and visits, as well as the number of cited articles

Maximum dissemination of your research work

Submit your manuscript at: http://papersubmission.scirp.org/

Or contact ojneph@scirp.org 